\title{
ADOLESCENTES PODEM SER ALUNOS IDEAIS?
}

\author{
Maria de Fátima de Souza Santos* \\ Fátima Maria Leite Cruz" \\ Rosemberg Belém***
}

RESUM0: A pesquisa investigou as representações sociais de adolescentes e de aluno ideal segundo professores de Ensino Médio e relacionou os sentidos à disciplina/indisciplina. Adotou-se a Teoria das Representações Sociais e os sujeitos foram 30 professores e estudantes de quatro escolas de Recife. Como recursos investigativos: Questionário de Associação Livre; Questionário de hierarquização das palavras evocadas; Entrevistas. $\mathrm{Na}$ análise, usamos o software Evoc para os questionários e na hierarquização e justificativas das entrevistas, o software Alceste. Encontramos distintas representações de aluno ideal e de adolescente, sem relação entre si, e com sentidos opostos. O compartilhamento de negatividade relaciona o aluno adolescente à indisciplina, representação oposta ao aluno ideal, justificada pela ausência de perspectiva de futuro, perdidos e desrespeitosos. Os alunos adolescentes obedientes consolidam a idealização do aluno ideal: quem planeja seu futuro no presente. Os adolescentes sinônimos de incivilidade inviabilizam projetos de emancipação e cidadania pela educação escolar.

Palavras-Chave: Adolescente. Aluno ideal. Representações Sociais. Disciplina /Indisciplina.

\footnotetext{
* Doutora em Psicologia PELA Université de Toulouse Le Mirail; Professora Titular em Psicologia da Universidade Federal de Pernambuco (UFPE )e Bolsista de Produtividade do Conselho Nacional de Desenvolvimento Científico e Tecnológico (CNPq).E-mail: mfsantos@ufpe.b

* Doutora em Educação pela Universidade Federal de Pernambuco )UFPE); Professora Adjunto da Universidade Federal de Pernambuco (UFPE). E-mail: fatimasan@uol.com.br

*** Mestre em Psicologia pela Universidade Federal de Pernambuco (UFPE); Professor da Faculdade de Ciências Humanas Esuda e da Faculdade Joaquim Nabuco. E-mail: bergbelem@hotmail.com
} 
ABSTRACT: This research investigated not only adolescent social representations but essentially the ideal student according to high school teachers, by associating meanings to discipline/indiscipline. By adopting the Theory of Social Representations, 30 teachers and students from four different schools in Recife, Pernambuco participated. The Free Association Survey - FAS, the evoked words hierarchy questionnaire and interviews were used as resources methods. At the analysis stage, EVOC software was applied to the free association survey and ALCESTE software was employed in order to justify the hierarchy on the interviews. Distinct representations of ideal student and adolescent were observed, without relationship to them as well as on opposite meanings. Negativity sharing relates adolescents to indiscipline, opposite representation to the ideal student, justified by the lack of future perspective, lost and disrespectful students. Obedient adolescent students consolidate the idealization of the ideal student: those who plan their future in the present. For these reasons, adolescents, incivility synonym, become unviable for emancipation projects in addition to citizenship through school education.

Keywords: Adolescent. Ideal student. Social representations. Discipline/ indiscipline.

\section{INTRODUÇÃO}

O título deste artigo embora pareça uma pergunta de fácil resposta que denota, apenas, uma linha provocativa à reflexão do leitor traz o questionamento que guiou a investigação da pesquisa aqui relatada, recorte do trabalho desenvolvido por Belém (2008). O foco nas representações de adolescente e de aluno ideal por professores do Ensino Médio foi a estratégia adotada como tentativa de compreender os sentidos ancorados na relação professor-aluno, um dos ângulos de análise que se relacionam aos fenômenos da disciplina/indisciplina na situação escolar.

Questionamos no estudo matriz: como os professores do Ensino Médio que lidam com adolescentes representam estes sujeitos? O que significa para um professor o aluno ideal? Seria o adolescente "naturalmente" indisciplinado? Pesquisas anteriores (SANTOS; ALÉSSIO, 2006; ALMEIDA; CUNHA; SANTOS, 2004; ALMEIDA; CUNHA, 2003, e.g.) fizeram emergir uma ideia, aparentemente consensual entre os adultos, de que a adolescência seria uma fase "natural" de rebeldia e transgressão e, de certa forma, 
os dados da realidade social contemporânea que são divulgados pela mídia corroboram este ideário, frequentemente, ao associar este grupo aos episódios de violência, ao uso de drogas e a uma gama variada de comportamentos considerados inadequados ou inaceitáveis pelo conjunto da sociedade.

No estudo que subsidiou as reflexões adiante apresentadas, foram encontradas diferentes concepções de adolescência e de indisciplina, entre os participantes, em dois contextos de escolas. Os resultados daquele estudo e as contradições entre a realidade e a idealização nos levaram a problematizar outro debate: para os professores, o adolescente pode ser um aluno ideal? Iniciamos o aprofundamento da temática, circunscrevendo alguns dos teóricos que abordam os fenômenos da indisciplina e da violência.

\section{INDISCIPLINA E VIOLÊNCIA: ALGUNS ESTUDOS NA ÁREA}

Numa incursão à literatura de violência e/ou indisciplina, sobretudo no âmbito escolar, encontramos que, no Brasil, a preocupação com a temática se iniciou, a partir dos anos 1980, como repercussão de um novo olhar para a qualidade de vida, juntamente com os processos de redemocratização do país. Considerava-se violência escolar, naquela ocasião, a depredação do patrimônio e do espaço público (ABRAMOVAY, 2003). Mesmo com a predominância desta perspectiva, naquela ocasião, Sposito (2001) realizou um estudo, já considerado clássico, de comportamentos violentos no âmbito escolar e encontrou que a violência se expressava na escola, porém seria motivada por aspectos externos à instituição escolar.

A partir dos anos 1990, o foco de análise da violência se voltou para o interior da escola e foi interpretada como resistência aos modelos autoritários nos estudos de Debarbieux e Blaya (2002) e Abramovay (2003). Zechi (2008), por outro ângulo, analisou os anos de 1990 a 2003 e encontrou, nas pesquisas acadêmicas, a violência apresentada como repercussão da violência social e da geopolítica das periferias dos grandes centros urbanos. Desta feita, a análise trouxe o foco explicativo para a formação de professores na perspectiva de redimensionar a qualificação, considerada deficitária, para a intervenção e o enfrentamento do fenômeno.

$\mathrm{Na}$ escola, a ampliação da violência por meio de expressões variadas entre grupo de alunos, o estudado fenômeno bullying (COUTINHO; RAMOS, 2008), e entre alunos e professores, mobilizaram políticas públicas de superação e enfrentamento, tais 
como o Programa Paz nas Escolas, da Secretaria Nacional de Direitos Humanos de 1999 (SPOSITO, 2001). Na relação indisciplina e violência na escola, Dayrell et al. (2009) apontam que suas expressões são formas políticas de afirmação do direito ao reconhecimento do aluno enquanto sujeito social.

Malta et al. (2010), numa pesquisa nacional sobre violência, segundo os estudantes, encontraram a violência física como a mais recorrente; na questão de gênero, os meninos se mostraram mais envolvidos em conflitos; não houve diferenciação a partir dos contextos de escolas, pública e privada; e a raiz da violência é explicada como culpa da família ou de sua ausência. Mais recentemente, Sastre (2013) levantou produções científicas sobre violência e indisciplina no contexto escolar brasileiro, e apresenta o aumento da violência circunstanciado ao contexto sócio-histórico e, em particular, ao desenvolvimento econômico do país, o que acarretou aumento populacional, migração urbana e o aprofundamento das desigualdades sociais. O autor destaca, ainda, a inexistência de investimentos para rastrear de modo sistemático a extensão do fenômeno, a despeito do reconhecimento de iniciativas da UNESCO, via Observatório de Violências na Escola, e alguns programas governamentais e institucionais. A violência é tema tão polêmico quanto as adolescências que discorreremos, a partir deste ponto.

\section{AS ADOLESCÊNCIAS E SUAS MÚLTIPLAS CONCEPC̣ÕES}

A adolescência se constitui hoje um importante objeto em torno do qual se discutem questões importantes de saúde, educação e segurança pública. Muitas vezes associada à droga, à transgressão e à violência (SANTOS; ALESSIO, 2006; CÂMARA, 2005; BENET'TI et al., 2006; BIASOLI-ALVES; AMPARO; CÁRDENAS; CHAVES; OLIVEIRA, 2007; DELL'AGLIO; DALBEM, 2008; COUTINHO; RAMOS, 2008), a adolescência foi construída socialmente como uma etapa especial do desenvolvimento à qual se associam expectativas, valores, normas de conduta, atribuições de comportamentos, sentimentos e intenções (OZELLA, 2003; MENANDRO, 2004; CASTRO; CORREA, 2005; BOCK, 2007; CASTRO, 2007).

Foi somente a partir do século XX, entretanto, que a adolescência se cristalizou como uma fase específica do desenvolvimento. Segundo Almeida (2005, p. 221), "Diferentes explicações têm sido formuladas no universo da ciência para tornar compreensível o surgimento desta noção, que assume força de realidade psíquica e social no século XX”. 
Ainda segundo a autora, no século XVIII os jovens eram destacados como coletivo social, pela necessidade do exército de recrutá-los para a carreira militar; em seguida, a necessidade de mão de obra qualificada para um mundo em processo de industrialização torna os jovens alvo dos Sistemas Nacionais de Ensino. Com a Revolução Industrial, que se fortalecia num vertiginoso ritmo de expansão, a ideia foi de expandir a escolarização com o intuito dessa capacitação requerida.

Progressivamente, a ideia da educação escolar, como instância preparatória para a inserção no mundo produtivo e para o futuro, foi sendo revestida da dimensão simbólica de garantia para a mobilidade social dos filhos de trabalhadores que seguiriam o mesmo estilo de vida do patronato. Passou-se, então, a atrasar a passagem da infância à "adultez", que anteriormente era tecida no ambiente doméstico em coautoria com os adultos, a partir dos trabalhos artesanais. Assim, foi se constituindo uma nova fase do desenvolvimento humano, com características bem peculiares, nas quais:

... são elaborados conceitos que irão diferenciar objetivamente a infância da adolescência. Contudo, nesse esforço para identificar parâmetros e associá-los ao comportamento do adolescente, surge claramente a percepção da adolescência como a "idade do perigo" (ALMEIDA, 2005, p. 222).

A ideia compartilhada da adolescência como sinônimo de turbulência vem sendo construída no próprio bojo de discussão teórica da Psicologia, tal qual foi descrita pela Psicologia do Desenvolvimento (ABERASTURY, 1980; ABERASTURY; KNOBEL, 1981) elargamente disseminada, tipificando a adolescência em normal e patológica. Ozella (2003), ao entrevistar psicólogos, mostrou que a maioria dos entrevistados compreende a adolescência como uma etapa da vida que faz parte da natureza humana, uma visão "naturalista e universal" dessa "etapa" caracterizada como uma fase conturbada, problemática, indefinida e difícil.

Calligaris (2000), por sua vez, destaca que a adolescência encerra um período de tensões e de possibilidades que tanto é permeado pelo repertório de significados da cultura, quanto por referenciais que singularizam a espécie humana. E ambos recebem o controle e a sedução de interesses diversos, portanto, tornam-se susceptíveis às demandas dos modos de ser e estar no mundo, que se tornam predominantes num dado contexto socioespacial, político e temporal. Num estudo realizado na zona rural do nordeste brasileiro, Santos e Aléssio (2006, p. 123) destacam este sentido contingencial: 
... se na zona urbana pais e professores concebem a adolescência como fase de rebeldia e dificuldades, na zona rural os pais destacam essa fase como o momento do trabalho e da constituição familiar, logo, conformidade aos valores e regras sociais.

Por esse motivo, alguns autores falam em "adolescências brasileiras", na tentativa de abarcar as diferentes possibilidades de ser adolescente em diferentes contextos sociais (CASTRO; CORREIA, 2005), o que resulta em uma perspectiva política de análise, incluindo o cotidiano, os processos comunicativos e a cultura, como previsto na abordagem psicossocial da Teoria das Representações Sociais que discutimos adiante.

\section{A TEORIADASREPRESENTAC̣ÕESSOCIAISEOSSENTIDOSCOMPARTILHADOS NO SENSO COMUM}

Para responder às questões da pesquisa, utilizou-se como quadro teórico de referência a Teoria das Representações Sociais (TRS) que visa investigar as teorias de senso comum, construídas nas práticas sociais, por meio dos processos comunicativos. Para Moscovici (2003), as representações sociais são orientadoras dos comportamentos e das comunicações entre os diferentes atores sociais (SANTOS, 2005) e têm a função de dar sentido à realidade social, organizar a comunicação e a conduta dos membros de um determinado grupo social.

Oestudo das Representações Sociais (RS) enfatiza a organização interna das representações e suas relações com a prática social. Abric (1987) propôs inicialmente a ideia de que as representações sociais são formadas por dois componentes organizados e complementares: o núcleo central e o sistema periférico. Enquanto o sistema central tem um papel normativo, o sistema periférico é essencialmente funcional. O núcleo central seria o elemento fundamental da representação uma vez que determina seu significado e sua organização interna; é constituído pelos elementos mais estáveis das RS e mais resistentes à mudança; são fortemente marcados pela memória coletiva do grupo e pelo sistema de normas e valores ao qual se referem.

Por outro lado, os elementos periféricos são estruturados em torno do núcleo central e em relação direta, moldados pelo contexto imediato, permitindo identificar possíveis diferenças individuais entre os sujeitos que compartilham determinada representação. Por esses elementos, as RS podem se ancorar na realidade imediata, com a função que Abric denomina de concretização do sistema central na 
tomada de posição ou de conduta, além de regulação e adaptação às exigências da situação. Entre os elementos próximos ao núcleo central, Abric diferencia dois tipos: aqueles de frequência alta, mas considerados pouco importantes pelos sujeitos, e aqueles de frequência baixa, mas considerados muito importantes pelos sujeitos. A esses últimos, o autor denominou elementos de contrastes:

... encontramos temas enunciados por poucas pessoas (freqüência baixa), mas que os consideram muito importantes. Esta configuração pode revelar a existência de um sub-grupo minoritário portador de uma representação diferente, isto é, cujo núcleo central seria constituído pelo elemento (ou os elementos) presente nesta casa, além do núcleo central apreendido na primeira casa (ABRIC, 2003, p. 6).

Com base na perspectiva estrutural, buscou-se investigar o conteúdo e a estrutura das representações sociais de adolescente e de aluno ideal.

\section{MÉTODO}

Na pesquisa, foram investigados 30 professores e estudantes de Ensino Médio de quatro escolas da cidade do Recife, sendo duas escolas privadas e duas escolas públicas. As escolas privadas reuniam alunos de camadas médias e média alta e situam-se nas zonas norte e sul da cidade, enquanto as escolas públicas atendiam uma população oriunda de camadas economicamente desfavorecidas e se situam em bairros de periferia.

No que se refere ao material e aos procedimentos de coleta, os professores responderam a um questionário de associação livre com dois termos indutores: adolescente e aluno ideal, usados como estratégia para relacionar os sentidos dessas representações à situação da disciplina/indisciplina escolar. $\mathrm{Na}$ instrução, foi solicitado a cada participante que escrevesse as quatro primeiras palavras que lhe viessem à mente quando lia cada termo indutor. Em seguida, hierarquizaram as palavras, por ordem de importância entre as registradas, justificando suas escolhas, não apenas pela ordem de evocação, mas pela importância que lhe atribuem (ABRIC, 1994).

Quanto aos procedimentos de análise, os dados obtidos por meio da associação livre, foram tratados com o software EVOC com o objetivo de delinear a estrutura da representação social. Este software utiliza dois parâmetros de análise: a frequência com que uma palavra é associada ao termo indutor e a ordem de importância das palavras associadas. Desse modo, desenha a estrutura da representação social 
com os seus elementos da zona central e os elementos do sistema periférico. Em seguida, as justificativas para as escolhas das palavras mais definidoras do termo indutor foram tratadas com o apoio do software ALCESTE, que realiza uma Classificação Hierárquica Descendente (C.H.D.) que permite a análise de classes de palavras hierarquizadas.

\section{RESULTADOS E DISCUSSÃO}

\section{A representação do aluno ideal}

A partir do termo-indutor aluno ideal, várias palavras foram evocadas, umas mais frequentes e outras menos, algumas nas primeiras posições e outras nas últimas em função da ordem de importância dada pelos sujeitos. O resultado é demonstrado na tabela abaixo.

TABELA 1: Frequência e ordem média de importância de palavras para 0 termo indutor "aluno ideal" $(\mathrm{N}=30)$.

\begin{tabular}{|c|c|c|c|}
\hline \multirow{4}{*}{$\begin{array}{l}\mathbf{F} \\
\mathbf{R} \\
\mathbf{E} \\
\mathbf{0} \\
\mathbf{U} \\
\hat{\mathbf{E}} \\
\mathbf{N} \\
\mathbf{C} \\
\mathbf{I} \\
\mathbf{A}\end{array}$} & & \multicolumn{2}{|c|}{$\begin{array}{ccc}\text { ORDEM MÉDIA } & \text { DE } \\
\text { IMPORTÂNCIA } & \\
\end{array}$} \\
\hline & & INFERIOR A 3,6 & SUPERIOR OU IGUAL A 3,6 \\
\hline & $\begin{array}{l}\text { ACIMA DE } \\
04\end{array}$ & 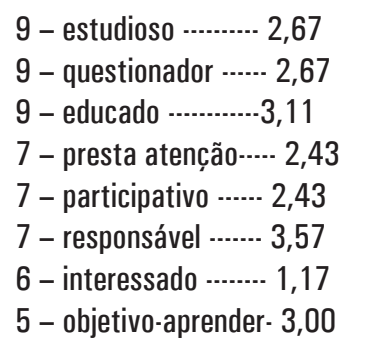 & 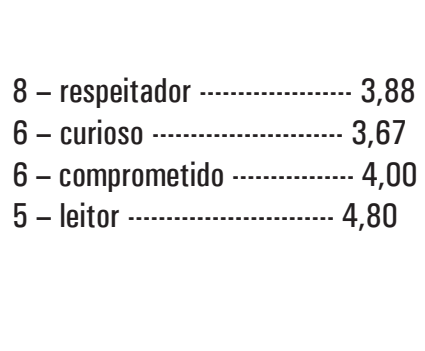 \\
\hline & $\begin{array}{l}\text { IGUAL OU } \\
\text { INFERIOR } \\
\text { A } 04\end{array}$ & 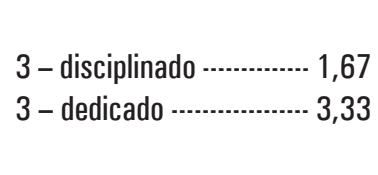 & 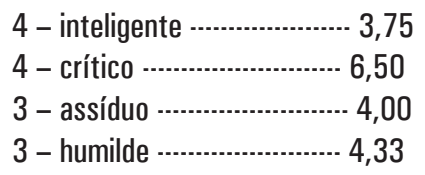 \\
\hline
\end{tabular}

As palavras mais consensuais pelo quantitativo de recorrências e pela importância atribuída pelos sujeitos que deram o sentido da representação podem ser vistas no primeiro quadrante: estudioso, questionador, educado, presta atenção, participativo. Essas palavras parecem nos revelar o aluno ideal como a imagem da excelência da aprendizagem escolar, expressa nas atitudes do aluno relacionadas às atividades acadêmicas, como também foi encontrado por CRUZ 
(2006), e naquela pesquisa, o aluno ideal foi representado como aquele, exclusivamente, oriundo da escola particular. As justificativas se concentraram nos aspectos cognitivos e comportamento considerado adequado ao âmbito escolar: respeitador e disciplinado. Esses dois termos juntos transmitem uma ideia de civilidade e, ao mesmo tempo, são sugestivos da obediência ou submissão típicas de relações educativas mais conservadoras.

$\mathrm{Na}$ educação escolar esta díade pode significar o distanciamento de práticas que favoreçam a autonomia e reforcem a postura de subserviência e passividade do aluno às orientações do contexto escolar e do professor, como se a situação de controle fosse condição indispensável para que as aprendizagens sejam efetivadas. $\mathrm{Na}$ tentativa de aprofundamento dessa compreensão, vimos que os termos evocados pelos professores em relação ao aluno ideal parecem se organizar em torno de três eixos: intelectual, comportamento "adequado" e relações sociais.

Novamente, emerge o sentido de que a cognição e a civilidade são relevantes e definidoras das aprendizagens na escola, contudo, ao justificarem os motivos de suas escolhas, ficou evidente que os professores enfatizaram o comportamento social do aluno, adequado/inadequado, como o marcador de sua condição de estudante, independente das aprendizagens escolares. Nas justificativas dos sujeitos, verificamos com o auxílio do software ALCESTE que havia três classes de respostas, como se observa no dendrograma a seguir (Fig. 2), sem diferença de posicionamento entre os professores de escolas públicas e privadas. Cada classe envolve um conjunto de palavras que aparecem juntas nos discursos dos sujeitos.

FIGURA 2: Dendrograma a partir das justificativas dos professores na expressão indutora aluno ideal

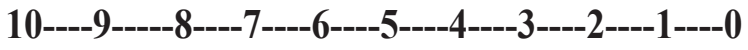

respeitador

Cl. 1 ( 12uce)

10 melhora o trabalho do professor

Cl. 2 ( 18uce) |

9 estudioso e pensa no futuro

Cl. 3 ( 14uce) 
A primeira classe foi situada separada das outras duas, ou seja, existe uma relação maior entre as classes 2 e 3 , ambas relativas à dimensão formal das relações estruturadas na sala de aula entre professor e aluno e que evocam um sentido positivo ao desempenho escolar e suas decorrências junto aos projetos de futuro. A classe 1, no entanto, parece mais relacionada a uma qualidade intrínseca ao aluno e o que ele apresenta na sala de aula, o que favorece a relação com os professores e com os outros alunos. Cada classe traz peculiaridades que são importantes na compreensão mais abrangente da relação entre a representação da adolescência e a de aluno ideal, por esse motivo, cada uma será analisada separadamente.

\section{O aluno ideal é respeitador}

O primeiro grupo de respostas destaca a importância do respeito na relação com o professor e com os outros alunos, e assume distintos sentidos: como base da relação, como base da aprendizagem, como posição social, como se tem nos exemplos:

O respeito é um princípio básico, e o aluno respeitador merece todo o apoio emocional e pedagógico.

A dedicação ocasionará maior conhecimento, sobretudo para se ter consciência de que não é detentor da verdade, respeitando assim os demais alunos e professores.

A disponibilidade para aprender, a consciência clara do objetivo que o faz estar na escola, o leva a desenvolver a dedicação, o respeito e a sociabilidade.

Identificamos diferentes sentidos para o aluno respeitador. Primeiro, os professores reconhecem $o$ respeito como um demarcador dos lugares sociais dos sujeitos na escola, quando dizem que o aluno respeitador merece todo o apoio emocional e pedagógico. Neste caso, estão dizendo, de modo subliminar, que há uma hierarquia nas relações sociais e no trato interpessoal na escola, e que esses diferentes posicionamentos repercutem no acompanhamento pedagógico que o estudante recebe. Em outro sentido, o respeito é entendido como humildade pelo reconhecimento do aluno de suas possibilidades e fragilidades, clareza que o leva a ser dedicado às suas aprendizagens e cordial nas interações. Esse conjunto de atributos que positiva a idealização de aluno nos diz, da mesma maneira, o que os professores 
representam como indisciplina: desrespeito ao professor e aos colegas, desafio às normas de civilidade, falta de dedicação às aprendizagens.

O entendimento é de que o respeito assegura a aprendizagem na educação escolar, e desta maneira, é requerida a atitude de humildade, diante do saber do outro, dos professores e dos colegas. Portanto, é a própria situação de aprendizagem e o reconhecimento da incompletude do ser humano que vão desenhando os contornos do respeito necessário para aprender: uma posição de investimento e interação com os pares que conduz à aprendizagem.

Ao contrário desses sentidos atribuídos ao aluno respeitador, a indisciplina se distancia desses sentidos, e os docentes questionam a qualidade das interações no cotidiano, como encontrado por CRUZ (2006). Naquele estudo, na escola pública, os alunos diziam que alguns professores desqualificavam a relação, pela diferença de pertença social entre professores e alunos, anunciavam que o professor com algumas atitudes também é desrespeitoso: ... ele falta, não dá aula, dir que tá na faculdade, não tá nem aí pra gente... Enquanto isso, na escola particular, eles relataram o mesmo sentido de diferenciação de atitude pela pertença social, e neste caso, a indisciplina é desrespeito quando os estudantes desqualificavam o professor pelo modo de vestir que consideravam impróprio para quem não é rico: ele que só quer ser o que não pode... todo de gravata...

Outro aspecto que encontramos em Belém (2008) referese ao reconhecimento de que os alunos desempenham um papel ativo no trabalho docente que é desenvolvido, ou seja, a qualidade da interação provocada pelo aluno ideal melhora o trabalho do professor, como se vê a seguir.

\section{O aluno ideal "melhora o trabalho do professor"}

Os professores revelaram que a qualidade do trabalho docente depende do aluno ideal, considerado como aquele que participa, questiona, explicita dúvida. Vejamos estes sentidos nas justificativas de suas escolhas:

$\mathrm{O}$ aluno questionador esclarece as dúvidas e incentiva o professor a buscar novos conhecimentos.

O aluno interessado estimula o professor.

... questionador, por desafiar o professor a buscar novos caminhos, propostas que venham ajudar as aulas a se tornarem melhores. 
normalmente quando o aluno é estudioso, também apresenta uma serie de qualidades esperadas de um bom estudante.

participativo, porque a partir dessa qualidade, o professor pode desenvolver outras habilidades e competências.

Os professores destacaram ainda que o aluno ideal é responsável por ressignificar a docência na sala de aula, porque ele mantém o professor incentivado e estimulado com o seu lugar de mediador na construção do conhecimento. Os sujeitos afirmam, ainda, que os questionamentos do aluno em relação ao conhecimento levam o docente a buscar novas propostas metodológicas para as aulas. Isso significa dizer que a prática docente é essencialmente interativa, em via de mão dupla, na qual a interlocução, a participação e a dúvida estruturam a construção das aprendizagens, e a relação de diálogo com os alunos desafia o professor e o instiga no seu fazer. Essa interatividade tanto mobiliza o professor em relação ao seu fazer, reconhecendo-se como um trabalhador intelectual, quanto potencializa as descobertas e achados dos alunos, como sujeitos autônomos (CRUZ, 1998, 2011). O repertório dessas experiências sugere que o aluno estudioso pode ter projetos de futuro.

\section{O aluno ideal é estudioso e pensa no seu futuro}

O terceiro grupo de justificativas destacou a responsabilidade individual do aluno em relação à sua aprendiaggem e na construção do seu futuro, como se apreende dos dados, a seguir:

um aluno que lê amplia seus conhecimentos, modifica para melhor sua visão de mundo.

O aluno ideal é aquele que está na escola em busca de uma formação para o seu futuro.

$\mathrm{O}$ aluno ideal tem que ter compromisso com o seu futuro, ser consciente de suas limitações e ser aplicado para transformar as suas pequenas derrotas em uma grande vitória.

O aluno ideal é aquele que é responsável em seus deveres e tem participação direta nos questionamentos referentes aos assuntos explanados.

Os participantes apresentaram o bábito da leitura, a responsabilidade com seus deveres e estudar, além de pensar no seu futuro, 
como alguns dos outros aspectos que compõem o perfil que foi definido na representação de aluno ideal. Pareceu-nos que a teoria construída pelo grupo de professores participantes contempla aspectos comportamentais em relação à aprendizagem, e menos, os relacionados aos aspectos formais dos conteúdos. Ou seja, a aprendizagem dos conteúdos escolares e o bom aproveitamento nas avaliações seriam repercussões dessas atitudes positivas em relação à aprendizagem que se concretizam com a participação em sala, a responsabilidade com as atividades, a leitura e o respeito. Dessa maneira, o desenho do aluno ideal, concretizado em comportamentos proativos e autônomos define a possibilidade e o compromisso do sujeito com um projeto de futuro, e mais ainda, a sua viabilidade no mundo da vida, além da apropriação dos saberes formais.

Os professores enfatizaram características pessoais relacionadas ao aluno ideal, expressas em palavras, tais como: estudioso, responsável, aplicado, consciente das limitações, participação, perseverança, entre outras. Para eles, um rendimento escolar satisfatório, vai além do desempenho acadêmico e não parece necessariamente revelado pelos resultados das provas, mas por comportamentos e um conjunto de atitudes que expressam o desejo de aprender e o investimento em relação ao próprio futuro expressos nas palavras respeito e uma vontade de aprender em função do futuro.

Os professores parecem revelar concepções mais construtivistas nas quais o foco não é, exclusivamente, o conteúdo, nem o resultado das provas per si, mas o processo e a formação de um ser pensante, que se constrói em autoria e coautoria no cotidiano da sala de aula, cujo interesse e participação acenam como está construindo as aprendizagens e o seu futuro. Em outras palavras, os professores parecem conceber a aprendizagem de uma forma mais abrangente.

Todavia, não se sabe se este enfoque é apenas nos discursos sobre a prática, ou se de fato essa concepção já se efetiva em moldes mais progressistas, especialmente, no que se refere ao Ensino Médio, diante da competitividade do ranqueamento educacional. Ao entrelaçar os dados encontrados, investigamos o cotejo das respostas dos professores ao questionário de associação livre, quando tiveram como expressão indutora aluno ideal e quando receberam a expressão indutora adolescente, esta última que pode ser visualizada na tabela abaixo. 
TABELA 2: Frequência e ordem média de importância de palavras - termo indutor "adolescente" ( $\mathrm{N}=30)$

\begin{tabular}{|c|c|c|c|}
\hline & & $\begin{array}{l}\text { ORDEM } \\
\text { IMPOI }\end{array}$ & $\begin{array}{l}\text { IÉDIA } \\
\text { IÂNCIA }\end{array}$ \\
\hline & & INFERIOR A 3,5 & SUPERIOR OU IGUAL A 3,5 \\
\hline $\mathbf{F}$ & $\begin{array}{c}\text { ACIMA } \\
\text { OU IGUAL } \\
\text { A } 4\end{array}$ & 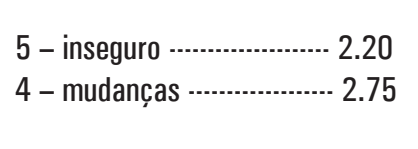 & 4 - irresponsável …………-...- 3.50 \\
\hline $\begin{array}{l}\text { E } \\
\mathbf{0} \\
\text { U } \\
\hat{E} \\
\text { N } \\
\text { C } \\
\text { I } \\
\text { A }\end{array}$ & $\begin{array}{c}\text { INFERIOR } \\
\text { A } 4\end{array}$ & 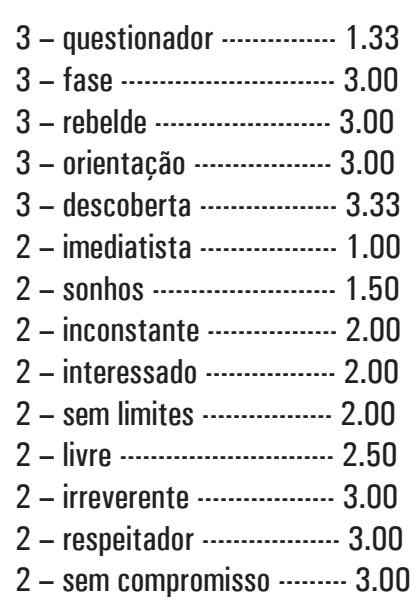 & 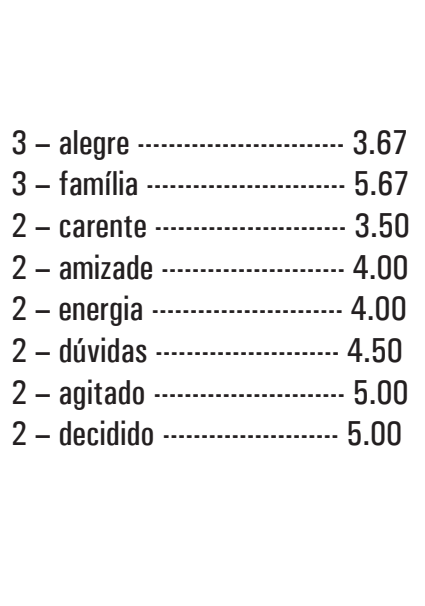 \\
\hline
\end{tabular}

Diversos aspectos na estrutura representacional da indisciplina foram associados à palavra adolescente. Uma primeira reflexão nos remete à ambiguidade que apareceu, tanto nas justificativas dadas pelos professores, como na dos alunos. Por um lado, há prevalência dos sentidos de insegurança e a irresponsabilidade e ainda chamam a atenção os termos rebelde, imediatista, inconstante e sem compromisso, que destacam um lado "negativo" da adolescência, comumente visto como 'aquele que não quer nada'. Por outro, as palavras sonhos, livre, respeitador, alegria, decidido, que aparecem na zona de contraste, revelam mais positividade. Tal constatação nos sugere que a adolescência é uma representação difícil de circunscrever.

Nas justificativas, visualizamos outras possíveis interpretações. Como se pode observar na figura a seguir (Fig. 2), aparecem três classes, duas mais relacionadas (classe 1 e 3 ), que tratam a adolescência como uma fase, sendo o adolescente de hoje diferente do adolescente de 
tempos atrás. Já a classe 2 descreve características do adolescente, mais associadas ao sentido de transgressão, que também foi apresentado pelo coletivo na primeira fase do estudo. Vejamos o dendrograma, a seguir.

FIGURA 2: Dendrograma construído a partir das justificativas dos sujeitos na palavra indutora "adolescente"

\section{Uma fase}

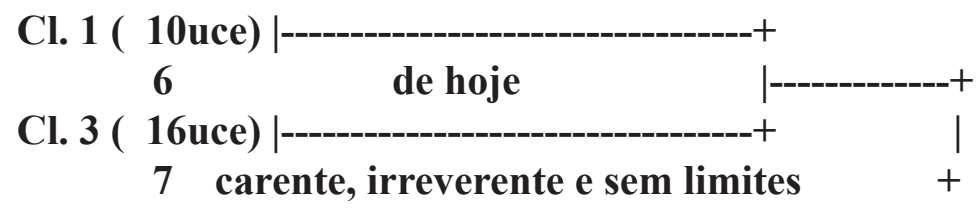

\section{Cl. 2 ( 10uce)}

\section{A adolescência é uma fase difícil (Classe 1)}

O primeiro grupo de justificativas apresenta o adolescente como uma pessoa em transição, ou seja, passando por uma fase, entretanto, esta não é uma fase qualquer, pois é caracterizada pela dificuldade, inquietação, complicada, características descritas como turbulências próprias dessa faixa etária. Os exemplos a seguir ilustram esta concepção:

como se trata de uma passagem de fase da infância para a fase adulta, o adolescente lembra muita energia, inquietação.

O adolescente é sempre complicado, pois está em uma fase difícil da vida. Está descobrindo o mundo, a realidade, mas ainda está sonhando.

... pois ele busca uma afirmação, uma notoriedade presente diante da mutação inerente ao seu ser, ao seu todo.

Nesses recortes, fica nítida a imagem da adolescência como uma fase, uma passagem transitória entre a infância e a vida adulta, expressiva das ideias do senso comum que a relacionam à complexa descoberta e vivência da realidade, distanciando-se da perspectiva de sonhos e fantasia que demarcam a imagem idealizada sobre a infância. A explicação para essa considerada mutação no desenvolvimento se baseia em pressupostos inatistas, ou seja, uma condição biológica que nasce com a pessoa, e é compreensível que tenha características negativas diante da sua necessidade de demarcação de um lugar social no mundo, daí a busca por afirmação e notoriedade. 
Em outras palavras, os dados nos autorizam a afirmar que a teoria construída pelos professores sobre o adolescente parece se ancorar na visão naturalista, ou seja, o entendimento é da adolescência como uma fase, que é inerente à natureza humana, com dificuldades também consideradas como típicas, e em certa medida, parecem uma tentativa de patologizar esse momento da vida. Contudo, é compartilhado que essa fase não é vivida igualmente, nos diferentes tempos históricos, e se configura diferentemente nas diferentes épocas, como foi apresentado na próxima classe.

\section{Os adolescentes de hoje não têm futuro}

No conjunto dos dados anteriores, os participantes apresentaram argumentos de que a adolescência é vinculada aos processos de transformação, entretanto, na hierarquização, quando a questão foi localizada pelo grupo nos tempos atuais, o enfoque adotado mudou. $\mathrm{O}$ adolescente de hoje é visto sem perspectiva do futuro, perdidos diante da quantidade de informações disponíveis, além de desrespeitosos, o que vislumbra perspectivas negativadas sobre o seu futuro, exceto para aqueles cuja obediência e disciplina os livram dos perigos da realidade, denominada de precipício, como se vê nos extratos a seguir elencados:

a meu ver, o maior problema que enfrentamos hoje com os adolescentes é a falta de perspectiva de futuro dos mesmos. estão recebendo muitas informações de qualquer forma. Os adolescentes ficam meio perdidos diante de algumas informações.

percebemos na atualidade que há um desrespeito muito grande dos adolescentes com seus pais e professores.

A obediência no adolescente é imprescindível, pois assim ele estará se livrando de ser participante de muitos caminhos que poderão levá-lo ao precipício.

Vemos que há persistência da ideia de transição que demarcou a psicologia, a adolescência e a escolarização, como vias de preparação lenta para o ingresso no mundo do trabalho, mesmo que, na atualidade, a ordem produtivista esteja sendo questionada em sua centralidade (RABELLO, 2007). Mesmo que de modo implícito, os dados sugerem alguns 'culpados' pela chamada crise em que se 
encontra o adolescente de hoje: ora a falta de projetos de futuro, ora o excesso de informações, ora a crise da autoridade que gera o desrespeito e a desobediência, e tais repercussões foram levadas pelos participantes para o âmbito das instituições responsabilizadas por sua formação, como a família e a escola.

Diante dessa situação, os professores destacaram a obediência como a solução para enfrentar o futuro, diante das perspectivas desfavoráveis do cenário de adversidades, de declínio e de "perdição" que a realidade oferece, e que foram sintetizadas na imagem metafórica do precipício.

No caso dos professores do Ensino Médio, essa negatividade atribuída ao adolescente de hoje provoca um sentido de desalento nesta relação, pelo fato de que precisarão conviver por todo o período de permanência dos adolescentes na educação escolar, com 0 desrespeito, o imediatismo, a falta de perspectiva do futuro, a inquietação dos jovens. Embora na associação livre tenham aparecido algumas palavras positivadas, tais como alegria, livre, amizade, interessado, estas foram esquecidas nesse momento em que a maioria dos sentidos foi fortemente negativado e justificado, como culpa do próprio adolescente.

A despeito dessa negatividade, o adolescente também ganhou outras características, cujos significados se distanciaram da culpabilização do adolescente e se tornaram mais próximos de explicações baseadas numa visão interativa e relacional da construção da subjetividade humana, como veremos agora.

\section{Adolescente carente, irreverente e sem limites}

Os adolescentes também foram vistos como carente, irreverente e sem limites. No entanto, as justificativas não culpabilizaram os adolescentes e se apoiaram em agentes externos, tais como a dimensão socioeconômica, a desintegração familiar, a falta de políticas públicas, como apresentamos, a seguir, nas falas dos professores:

creio que pelas circunstâncias socioeconômicas, pela desintegração da família e pela falta de políticas públicas adequadas, é que carente é a principal característica do adolescente de hoje.

A falta de limites de muitos jovens prejudica o trabalho do professor.

A irreverência é característica primordial na vida do adolescente. 
Vários aspectos podem ser discutidos nesta análise, pois aqui ficou mais nítida a relação da adolescência com a indisciplina. Em primeiro destaque, é pertinente a referência de que inexistem, ou existem muito recentemente e com fragilidades, as políticas públicas para a juventude. Ainda não se tem consolidada esta relação entre adolescência e a necessidade de intervenção do Estado na construção de projetos de futuro para este segmento. O que nos inquieta é que tal relação foi evidente na escola pública, como se a indisciplina só ocorresse naquele espaço, ou seja, a indisciplina tipificou o aluno adolescente pobre.

Outro ângulo de análise nos revelou que os professores parecem fixados em modelos idealizados de uma família nuclear, burguesa, e ao evocarem a imagem de família desestruturada, anunciam que desconsideram os arranjos e configurações contemporâneas de família, como apresentado por Cruz e Santos (2009). Novamente os resultados apontaram para a relação obediência/desobediência, como uma díade que é um obstáculo na relação professor-aluno, na perspectiva unilateral de que a desobediência atrapalha o trabalho docente.

A denominada falta de limites mereceria também uma discussão, haja vista que esta expressão se tornou um termo genérico, e que se emprega de modo similar para diferentes contextos e situações. O que se quer dizer com falta de limites? Qual é mesmo o limite? Quem colocaria estes limites? O que impede que estes limites sejam colocados? Este não é realmente um conjunto de questões de respostas fáceis, posto que envolve diferentes meandros a serem analisados, mas cabe a reflexão, considerando-se que, frequentemente, a falta de limites é anunciada pelos professores como um sinônimo de indisciplina, todavia, não é discutida a sua gênese, nem a sua superação.

\section{CONSIDERAC̣̃̃ES FINAIS}

Ao estudar as representações sociais de adolescência e de aluno ideal por professores do Ensino Médio e relacioná-las à disciplina/indisciplina, a tentativa foi de compreender os sentidos compartilhados e como estes se ancoravam à situação escolar. Para os professores investigados, há uma grande distância entre o adolescente e o aluno ideal e, por vezes, os definem a partir de conteúdos representacionais opostos. $\mathrm{O}$ adolescente pensado como irreverente, descomprometido, desrespeitador, despreocupado com o futuro é longe de um aluno ideal, que seria aquele que se preocupa com of futuro, contribui 
com o professor na sala de aula, respeita a todos, compromete-se e se interessa pelos estudos. Diante de tais contradições, pode-se mesmo afirmar que o adolescente não é representado como um aluno ideal.

A questão que os resultados provocam é exatamente a contradição, entre o pensado e o vivido. Ou seja, os alunos desses professores de Ensino Médio são adolescentes, por conseguinte, distanciados do que é idealizado como aluno por estes professores. Então, os alunos dos professores do Ensino Médio, por serem adolescentes, são representados como indisciplinados, portanto, não autorizados simbolicamente à qualidade na interação com os seus professores, embora a mediação tenha sido apresentada como condição favorável às suas aprendizagens.

De modo oposto à função social da escola, estas representações revelam que a atuação dos docentes pareceu-nos descontextualizada das mudanças sociais, e distanciam os professores da participação na construção coletiva de projetos de futuro para a juventude, a partir da educação escolar, pois eles não legitimam o adolescente da atualidade como um sujeito de aprendizagens. Fixados no aluno idealizado que inexiste, os professores desconsideram o vir-a-ser de possibilidades dos alunos-adolescentes, e até mesmo desautorizam sua inserção social, produtiva e realizadora. Nesta direção, podemos afirmar que se aprofunda o tensionamento na relação professor-aluno, posto que não há correspondência entre o comportamento que é idealizado pelos professores e a postura adolescente em sala de aula.

O sentido propositivo e mobilizador de características como curiosidade, criatividade, não acomodação e não submissão dos alunos, vetores que geraram as grandes mudanças e transformações no processo político e civilizatório da humanidade, bem como nos achados da ciência, assume sentido negativo para os professores e contribui na construção do repertório de crenças compartilhadas sobre uma adolescência tipificada, a priori, como eivada de rebeldia e indisciplina.

\section{REFERÊNCIAS}

ABERASTURY, A.; KNOBEL, M. Adolescência normal. Porto Alegre: Artes Médicas, 1981.

ABERASTURY, A. Adolescência. Porto Alegre: Artes Médicas, 1980.

ABRAMOVAY, M. Escola e violência. Brasília: UNESCO no Brasil, 2003.

ABRIC, Jean-Claude. Coopération, compétition et représentation sociale. Cousset: DelVal, 1987.

ABRIC, Jean-Claude. Pratiques sociales et représentations. Paris: P.U.F, 1994

ABRIC, Jean-Claude. La recherche du noyau central et de la zone muette des représentations sociales. In: ABRIC, Jean-Claude (Org.). Méthodes d'études des représentations sociales. Érès: Ramonville Saint-Agne, 2003. 
ALMEIDA, A. M. O. Os adolescentes em manchete (policial). In: PAVIANI, A.; FERREIRA, I. C. B.; BARRETO, F. F. P. (Orgs.). Brasilia. Dimensões da violência. Brasília: UnB, 2005. pp. 219-249.

ALMEIDA, A. M. O.; CUNHA, G. G. Representações sociais do Desenvolvimento Humano. Psicologia Reflexão e Crítica. Porto Alegre, 16 (1), p. 147-155, 2003.

ALMEIDA, A. M. O.; CUNHA, G. G.; SANTOS, M. F. S. Formas contemporâneas de pensar a criança e o adolescente. Estudos, Goiânia, v.31, n.4, p.637-660, 2004.

BELÉM, R. C. Representações sociais de indisciplina. 2008. Dissertação (Mestrado em Psicologia) - UFPE, Recife, 2008.

BENETTI, S. P. C. et al. Violência comunitária, exposição às drogas ilícitas e envolvimento com a lei na adolescência. Psico, Porto Alegre, 37(3), 276-286, 2006.

BIASOLI-ALVES, P. et al. Instituições de atendimento socioeducativo a adolescentes em situação de risco do Distrito Federal: Panorama e perspectivas. Psico, Porto Alegre, 38(2), 166-176, 2007.

BOCK, A. M. A adolescência como construção social: estudo sobre livros destinados a pais e educadores. Revista Semestral da Associação Brasileira de Psicologia Escolar e Educacional (ABRAPEE), Maringá, v. 11, n. 1, Janeiro/Junho 2007, p. 63-76.

CALLIGARIS, C. A adolescência. São Paulo: Ed. Publifolha, 2000.

CAMACHO, L. M. Y. As sutilezas das faces da violência nas práticas escolares de adolescentes. Educação e Pesquisa, São Paulo, 27(1), 123-140, 2001.

CÂMARA, S. G. Comportamentos de risco entre jovens. Psico, Porto Alegre, 36, 1, 89-97, 2005.

CASTRO, L. R. de. A politização (necessária) do campo da infância e da adolescência. Rev. psicol. polit., v.7, n.14, São Paulo, dez, 2007.

CASTRO, L. R. de; CORREA, J. Juventudes, transformações do contemporâneo e participação social. In: CASTRO, L. R. de; CORREA, J. (Orgs.). Juventude contemporânea: perspectivas nacionais e internacionais. Rio de Janeiro: NAU - FAPERJ, 2005.

CHARLOT, B. Pour le savoir, contre la stratégie. In: DUBET, F. (Org.).École, famille: le malentendu. Paris: Éditions Textuel, 1997. p. 59-78.

CHARLOT, B. Relações e saberes na escola: uma leitura em positivo. Revista Expressão, v. 1, n. 41.

COUTINHO, M. P. L.; RAMOS, N. Distúrbios psicoafetivos na infância e adolescência: um estudo transcultural. Psico, Porto Alegre, 39, 1, 14-20, 2008.

CRUZ, F. M. L. Múltiplos olhares: a prática pedagógica por quem a realiza. Dissertação (Mestrado em Educação) - Centro de Educação, UFPE, Recife, 1998.

CRUZ, F. M. L. Expressões e significados da exclusão escolar: representações sociais de professores e alunos sobre o fracasso em matemática. 2006. Tese (Doutorado em Educação) - Programa de Pós-Graduação em Educação, Centro de Educação, UFPE, Recife, 2006.

CRUZ, F. M. L.; SANTOS, M. F. A relação família e escola: fronteiras e possibilidades. Revista de Educação pública, Cuiabá, vol. 17 (35), p.443-454, 2008.

CRUZ, F. M. L.; MAIA, L. S. L. Genialidade e loucura nas representações sociais do professor de matemática segundo estudantes e professores. Práxis Educativa, Ponta Grossa, v.6, n.2, p. 235-247, jan.-jun. 2011. Disponível em <http://www.periodicos.uepg.br. Acesso em: 15 de outubro de 2012 .

DAYRELL, J.T. et al. Juventude e escola. In: SPOSITO, M.P. O estado da arte sobre juventude na pós-graduação brasileira: Educação, Ciências Sociais e Serviço Social (19992006). Belo Horizonte: Argumentum, 2009. 
DEBARBIEUX, E.; BLAYA, C. Violência nas escolas e políticas públicas. Brasília: UNESCO, 2002. DELL'AGLIO, D. D.; DALBEM, J. X. Apego em adolescentes institucionalizadas: processos de resiliência na formação de novos vínculos afetivos. Psico, Porto Alegre, 39(1), 34-40, 2008.

MALTA, Deborah Carvalho et al. Bullying nas escolas brasileiras: resultados da Pesquisa Nacional de saúde do escolar (PENSE), 2009. Ciência e Saúde Coletiva vol. 15 supl. 2. Rio de Janeiro:out.2010.Disponívelem: http://www.scielo.br/scielo.php?script=sci_ arttext\&pid=S1413-81232010000800011. Acesso em: 06 de junho de 2014

MENANDRO, M. C. S. Gente jovem reunida: um estudo de representações sociais da adolescência/juventude a partir de textos jornalísticos (1968/1974 e 1996/2002). 2004. Tese (Doutorado) - Universidade Federal do Espírito Santo, Vitória, 2004.

MOSCOVICI, S. Representações sociais: investigações em psicologia social. Petrópolis, RJ: Vozes, 2003.

OZELLA, Sergio (Org.). Adolescências construídas: a visão da psicologia sócio-histórica. São Paulo: Cortez, 2003.

SANTOS, M. F, S.; ALÉSSIO, R. L. S. De quem é a culpa? Representações de pais das zonas urbana e rural sobre adolescência e violência. In: ALMEIDA A. M. O.; SANTOS, M. F. S. Violência, exclusão social e desenvolvimento humano. Estudos em representações sociais. Brasília: EdUNB, 2006.

SANTOS, M. F. S. A teoria das representações sociais. In: SANTOS, M. F. S.; ALMEIDA, L. M. (Org.). Diálogos com a teoria das representações sociais. Pernanmbuco: Ed. Universitária da UFPE, 2005. p. 13-38.

SASTRE, E. Panorama dos estudos sobre violência nas escolas no Brasil: 1980-2009. SECAD: MEC, 2013. Disponível em http://portaldoprofessor.mec.gov.br. Acesso em: 20 de fevereiro de 2014.

SPOSITO, M. Juventude, pesquisa e educação. ANPED, 2001.

ZECHI, J. A. M. Violência e indisciplina em meio escolar: aspectos teórico-metodológicos da produção acadêmica no período de 2000 a 2005. 2008. 152 f. Dissertação (Mestrado em Educação) - Faculdade de Ciências e Tecnologia, Universidade Estadual Paulista "Júlio de Mesquita Filho", Presidente Prudente, 2008.

Recebido: 24/11/2012

Aprovado: 01/08/2014

Contato:

Universidade Federal de Pernambuco Centro de Filosofia e Ciências Humanas

Departamento de Psicologia Av. da Arquitetura, s/n, $9^{\circ}$ andar Recife | Pernambuco | Brasil CEP 50.740-550 